\title{
Tumor Necrosis Factor-a, Caspase-9 and Heat Shock Protein 70 Expressions with Leukemia Inhibitory Factor in Hydrosalpinx
}

Hanom Husni Syam ( $\sim$ hanomhsyam@gmail.com )

Universitas Padjadjaran https://orcid.org/0000-0001-9799-5224

\section{Tono Djuwantono}

Universitas Padjadjaran

Jusuf S. Effendi

Universitas Padjadjaran

Ponpon S. Idjradinata

Universitas Padjadjaran

Tita H. Madjid

Universitas Padjadjaran

Wiryawan Permadi

Universitas Padjadjaran

Leri Septiani

Universitas Padjadjaran

Research article

Keywords: Hydrosalpinx, TNF-a, caspase-9, Hsp70 and LIF

Posted Date: March 3rd, 2020

DOl: https://doi.org/10.21203/rs.3.rs-15723/v1

License: (9) (i) This work is licensed under a Creative Commons Attribution 4.0 International License.

Read Full License 


\section{Abstract}

Background The leakage of hydrosalpinx fluid from the tube into the uterine cavity is likely to interfere with normal implantation. Hydrosalpinx fluids contain tumor necrosis factor-a (TNF-a), which induces caspase-9 signal transduction, leading to apoptosis. Endometrial cells inhibit apoptosis by synthesizing heat shock protein 70 (Hsp70). The TNF-a, caspase-9 and Hsp70 factors are closely related to apoptosis. In women with hydrosalpinx, the endometrial receptivity of embryonic implantation processes is low. Endometrial receptivity can be assessed by leukemia inhibitory factor (LIF). TNF-a, caspase-9 and Hsp70 expression plays an important role in endometrial receptivity disorders in women with hydrosalpinx.Materials and Methods These is an analytic observational, cross-sectional and categorical comparative study was conducted in 44 subjects with and without hydrosalpinx. The present study was performed in Dr. Hasan Sadikin Hospital, Grha Bunda-, Limijati-Maternity and Children Hospital (MayJune 2017). Immunohistochemistry was performed with a cutoff based on the ROC. The Mann-Whitney analysis was performed on TNF-a, caspase-9, Hsp70 and LIF in both groups, whereas a correlation regression test was performed to observe the correlation among these protein.Results The present study used the histoscore as a tool to evaluate the expression of variable between study groups. The comparison of the histoscore for parameters between hydrosalpinx and non-hydrosalpinx subjects was TNF-a (12 vs 9; $p<0,001)$, caspase-9 (12 vs 8,5; $p<0,001)$, Hsp70 (6 vs $8 ; p<0,001)$, and LIF (9 vs 12; $p<0,05)$, respectively.Conclusion The results showed a significant difference in TNF- $a$, caspase-9, Hsp70 and LIF ( $\mathrm{p}<0.05)$ between hydrosalpinx and non-hydrosalpinx patients. Caspase-9 and Hsp70 are interconnected and related to LIF as a marker in the endometrium receptivity by hydrosalpinx patients.

\section{Background}

Infertility rates continue to increase worldwide; based on a demographic and health survey by the World Health Organization in 2012, the burden of infertility is still high in women in 190 countries since the period 1990-2010; the number of couples with infertility increased from 42 million to 48.5 million [1]. In the demographic and health survey from the period 1994-2000, the percentage of Indonesian women (aged 15-49 years) with infertility was approximately $10.2 \%$ [2]. Approximately $25-35 \%$ of infertility cases in women are caused by tubal factors [3]. The majority of tubal factor infertility is caused by sexually transmitted diseases that result in pelvic inflammatory disease (PID) $[4,5]$. If left untreated, then PID can lead to chronic inflammation of the fallopian tubes causing blockage and fluid accumulation in the fallopian tubes, known as hydrosalpinx [5], which is a reproductive organ abnormality that affects the success rate of pregnancy.

The chemical composition of the hydrosalpinx fluid is not well known, but tumor necrotic factor-a (TNF-a) is consistently found in the fluid [6]. TNF-a is a multifunctional cytokine derived from the activation of macrophages that can eliminate microorganisms and tumor cells, thus modulating cellular proliferation, differentiation and immunoregulation [7]. TNF-a paracrine and endocrine properties cause TNF- $a$ to bind to receptors on the endometrium surface, further triggering signal transduction and inducing the conversion of procaspase- 9 to caspase-9, which then activates caspase-3 for the destruction of 
deoxyribonucleic acid (DNA) in the cell nucleus, leading to cell apoptosis [8, 9]. Endometrial cells regulate apoptosis by synthesizing chaperone proteins, such as heat shock protein 70 (Hsp70). Hsp70 is a cytoprotective protein associated with the inactivation of apoptosis. Hsp70 helps cells to survive by preventing protein denaturation, facilitating the transfer of proteins between organelles and cell membranes, and maintaining the integrity of regulatory proteins; when Hsp70 expression is high, this chaperone inhibits the process of apoptosis in the endometrium [10]. In hydrosalpinx patients, Hsp70 expression is low, so apoptosis in the endometrium increases.

Embryonic and endometrial relationships are essential for successful embryo implantation. Normal embryo implantation requires good endometrial receptivity. The implantation process is assisted by molecular groups, such as leukemia inhibitory factor (LIF), interleukin (IL) 1, IL-6, prostaglandin and cell adhesion molecules (CAMs). CAMs consist of integrin, cadherin, selectin or immunoglobulin [11]. The expression of LIF, the IL- 6 cytokine excreted by the endometrium, plays an important regulatory role in endometrial receptivity to the embryo, which plays a role in blastocyst implantation. LIF strengthens the regulation and differentiation of the trophectoderm and plays an important role in adhesion and blastocyst invasion during implantation. LIF is a well-studied factor related to endometrial receptivity to embryos [11]. In hydrosalpinx, endometrial receptivity is low, resulting in implant failure and eventually leading to infertility. From the above description, the expression of TNF-a, caspase-9 and Hsp70 plays an important role in the endometrial receptivity disorder (LIF) of hydrosalpinx patients; therefore, the present study will analyze the etiopathologic factors.

\section{Methods}

The accessible population in this study was patient with or without hydrosalpinx where diagnostic laparoscopy had been performed in Dr. Hasan Sadikin Hospital, Grha Bunda-, Limijati-Maternity and Children Hospital (May-June 2017). Immunohistochemistry (IHC) analysis was done using anti-TNF-a, caspase-9, Hsp70 and LIF antibodies. Staining was performed using a streptavidin-biotin method as described previously [12]. In brief, paraffin blocks were processed in 4- $\mu \mathrm{m}$-thick sections and were then incubated with fresh $0.3 \%$ hydrogen peroxide in methanol for 30 minutes at room temperature. After rinsing in phosphate-buffered saline (PBS; $\mathrm{pH} 7.4$ ), nonspecific binding sites were blocked by incubating with $10 \%$ normal serum for $30 \mathrm{~min}$. The specimens were then incubated with anti-TNF-a (2C8), caspase9 (E23) Hsp70 (EPR16892) or LIF (IMG39N7D10) Abcam monoclonal antibodies. The staining was scored semi-quantitatively as follows: total staining was scored as the staining intensity (on a scale of 1 + to $3+$ ) and distribution of staining; level $3+$ was the strongest and $1+$ is the lowest-staining intensity. A distribution of $<20 \%$ was scored $1,20-50 \%$ was scored $2,50-80 \%$ was scored 3 and $>80 \%$ was scored 4. Statistics analysis was performed using SPSS, ver. 16.0. p-values of $<0.05$ were significant.

\section{Results}

\section{Characteristics of Study Subjects}


The study subject characteristics were categorized into the hydrosalpinx and without hydrosalpinx; described on the basis of age and body mass index as shown in Table 1.

Table 1. Characteristics of Study Subjects

\begin{tabular}{|c|c|c|c|}
\hline \multirow[b]{2}{*}{ Characteristics } & \multicolumn{2}{|c|}{ Group } & \multirow[b]{2}{*}{ p-Value* } \\
\hline & $\begin{array}{l}\text { Hydrosalpinx } \\
(\mathrm{n}=24)\end{array}$ & $\begin{array}{c}\text { Non-hydrosalpinx } \\
(\mathrm{n}=24)\end{array}$ & \\
\hline Age (Years Old) & & & 0,311 \\
\hline$<30$ & 8 & 4 & \\
\hline $30-35$ & 10 & 10 & \\
\hline$>35$ & 6 & 10 & \\
\hline Body Mass Index & & & 0,807 \\
\hline Normal & 12 & 10 & \\
\hline Overweight & 10 & 11 & \\
\hline Obesitas & 2 & 3 & \\
\hline
\end{tabular}

Note: *) chi-kuadrat test

\section{TNF-a Endometrium Expression between Hydrosalpinx and Non-hydrosalpinx}

There is a difference of TNF- $a$ expression between hydrosalpinx and non-hydrosalpinx (Figure 1 and Table 2) based on color intensity, distribution of cell spreading per space view and histoscore value. Using Mann-Whitney test analysis, the results of TNF-a expression in the endometrium of the hydrosalpinx group were significantly greater $(p<0.05)$ than non-hydrosalpinx.

Table 2. TNF- $\alpha$ Endometrium Expression between Hydrosalpinx and Non-hydrosalpinx

\begin{tabular}{cccc}
\hline & \multicolumn{2}{c}{ Group } & p-Value* \\
\cline { 2 - 3 } TNF- $\boldsymbol{\alpha}$ & $\begin{array}{c}\text { Hydrosalpinx } \\
(\mathbf{n}=\mathbf{2 4})\end{array}$ & $\begin{array}{c}\text { Non-hydrosalpinx } \\
(\mathbf{n}=\mathbf{2 4})\end{array}$ & \\
\hline Intensity & & 5 & \\
Low & 0 & 12 & \\
Moderate & 21 & 7 & $<0,001$ \\
\hline Strong & 3 & 1 & \\
Distribution & 0 & 20 & \\
\hline $20-50$ & 0 & 3 & \\
$50-80$ & 0 & 9 & \\
\hline$>80$ & 24 & $6-12$ & \\
\hline Histoscore & & & \\
\hline Median & 12 & & \\
Range & $12-16$ & & \\
\hline
\end{tabular}

Note: * uji Mann-Whitney

Caspase-9 Endometrium Expression between Hydrosalpinx and Non-hydrosalpinx 
There is a difference of caspase-9 expression between hydrosalpinx and non-hydrosalpinx (Figure 2 and Table 3) based on color intensity, distribution of cell spreading per field view and histoscore value. Using Mann-Whitney test analysis; the expression of caspase-9 in the endometrium of the hydrosalpinx group was significantly greater $(p<0.05)$ than in the non-hydrosalpinx group.

Table 3. Caspase-9 Endometrium Expression between Hydrosalpinx and Non-hydrosalpinx

\begin{tabular}{cccc}
\hline & \multicolumn{2}{c}{ Group } & p-Value* \\
\cline { 2 - 3 } Caspase - 9 & $\begin{array}{c}\text { Hydrosalpinx } \\
(\mathbf{n}=\mathbf{2 4})\end{array}$ & $\begin{array}{c}\text { Non-hydrosalpinx } \\
(\mathbf{n}=\mathbf{2 4})\end{array}$ & \\
\hline Intensity & 1 & 11 & \\
Low & 16 & 11 & \\
Moderate & 7 & 2 & $<0,001$ \\
\hline Strong & 0 & 1 & \\
Distribution & 3 & 8 & \\
$20-50$ & 21 & 15 & \\
\hline $50-80$ & 12 & 8,5 & \\
\hline$>80$ & $8-16$ & $6-16$ & \\
Histoscore & & & \\
Median & & & \\
Range & & &
\end{tabular}

Note: * uji Mann-Whitney

\section{Hsp70 Endometrium Expression between Hydrosalpinx and Non-hydrosalpinx}

There is a difference in Hsp70 expression between hydrosalpinx and non-hydrosalpinx (Figure 3 and Table 4) based on color intensity, distribution of cell spreading per view space and histoscore value. Mann-Whitney test results showed that Hsp70 expression on endometrium of hydrosalpinx group was significantly smaller $(p<0.05)$ than non-hydrosalpinx group.

Table 4. Hsp70 Endometrium Expression between Hydrosalpinx and Non-hydrosalpinx

\begin{tabular}{|c|c|c|c|}
\hline \multirow[b]{2}{*}{ Hsp70 } & \multicolumn{2}{|c|}{ Group } & \multirow[t]{2}{*}{ p-Value* } \\
\hline & $\begin{array}{l}\text { Hydrosalpinx } \\
(\mathrm{n}=24)\end{array}$ & $\begin{array}{c}\text { Non-hydrosalpinx } \\
(\mathrm{n}=24)\end{array}$ & \\
\hline \multicolumn{4}{|l|}{ Intensity } \\
\hline Low & 17 & 15 & \\
\hline Moderate & 4 & 3 & \\
\hline Strong & 3 & 6 & \\
\hline \multicolumn{4}{|l|}{ Distribution } \\
\hline $20-50$ & 0 & 1 & \\
\hline $50-80$ & 24 & 2 & \\
\hline$>80$ & 0 & 21 & \\
\hline Histoscore & & & $<0,001$ \\
\hline Median & 6 & 8 & \\
\hline Range & $6-12$ & $6-16$ & \\
\hline
\end{tabular}

Note: *uji Mann-Whitney 
Table 4. Hsp70 Endometrium Expression between Hydrosalpinx and Non-hydrosalpinx Group p-Value*

\begin{tabular}{|c|c|c|c|}
\hline \multirow[b]{2}{*}{ Hsp70 } & \multicolumn{2}{|c|}{ Group } & \multirow[t]{2}{*}{ p-Value* } \\
\hline & $\begin{array}{l}\text { Hydrosalpinx } \\
(\mathrm{n}=24)\end{array}$ & $\begin{array}{c}\text { Non-hydrosalpinx } \\
(\mathrm{n}=24)\end{array}$ & \\
\hline \multicolumn{4}{|l|}{ Intensity } \\
\hline Low & 17 & 15 & \\
\hline Moderate & 4 & 3 & \\
\hline Strong & 3 & 6 & \\
\hline \multicolumn{4}{|l|}{ Distribution } \\
\hline $20-50$ & 0 & 1 & \\
\hline $50-80$ & 24 & 2 & \\
\hline$>80$ & 0 & 21 & \\
\hline Histoscore & & & $<0,001$ \\
\hline Median & 6 & 8 & \\
\hline Range & $6-12$ & $6-16$ & \\
\hline
\end{tabular}

Note: *uji Mann-Whitney

LIF Endometrium Expression between Hydrosalpinx and Non-hydrosalpinx

There is a difference of LIF expression between the hydrosalpinx and non-hydrosalpinx (Figure 4 and Table 5) based on the intensity of the color, the distribution of cell dispersion per field view and the histoscore value. Using Mann-Whitney test analysis, there was significant difference $(p<0.05)$ of LIF expression between endometrium of hydrosalpinx and non-hydrosalpinx group.

Table 5. LIF Endometrium Expression between Hydrosalpinx and Non-hydrosalpinx

\begin{tabular}{|c|c|c|c|}
\hline \multirow[b]{2}{*}{ LIF } & \multicolumn{2}{|c|}{ Group } & \multirow[t]{2}{*}{ p-Value* } \\
\hline & $\begin{array}{l}\text { Hydrosalpinx } \\
(\mathrm{n}=24)\end{array}$ & $\begin{array}{c}\text { Non-hydrosalpinx } \\
(\mathrm{n}=24)\end{array}$ & \\
\hline $\begin{array}{c}\text { Intensity } \\
\text { Low }\end{array}$ & 9 & 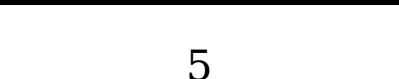 & \\
\hline Moderate & 7 & 11 & \\
\hline Strong & 8 & 8 & \\
\hline Distribution & & & \\
\hline $20-50$ & 0 & 3 & \\
\hline $50-80$ & 24 & 0 & \\
\hline$>80$ & 0 & 21 & \\
\hline Histoscore & & & 0,008 \\
\hline Median & 9 & 12 & \\
\hline Range & $6-12$ & $6-16$ & \\
\hline
\end{tabular}

Note: * uji Mann-Whitney

Correlation of TNF-a, Caspase-9 and Hsp70 with LIF Endometrium Expression between Hydrosalpinx and Non-hydrosalpinx 
The relationship of TNF-a, caspase-9 and Hsp70 with their effects on endometrial receptivity, in this case is LIF is described together in Table 6. Regression equation model is obtained: Histoscore LIF $=4,198+$ $(0.396 \times$ histoscore Hsp70) $+(0.365 \times$ histoscore Caspase- 9$) \otimes(2,805 \times$ Groups $)$. When viewed from its out-put: TNF-a does not contribute to the value of LIF; Hsp70 contributes in the value of LIF; caspase-9 contributed in the value of LIF.

\section{Table 6. Correlation TNF- $\alpha$, Caspase-9 dan}

Hsp70 with LIF Endometrium Expression between Hydrosalpinx and Nonhydrosalpinx

\begin{tabular}{cccccc}
\hline Variables & Coefisien B & Std. Error & Beta & t & p-Value \\
\hline Constanta & 4,198 & 2,064 & & 2,034 & 0,048 \\
Caspase-9 & 0,365 & 0,144 & 0,356 & 2,529 & 0,015 \\
\hline Hsp70 & 0,396 & 0,133 & 0,395 & 2,975 & 0,005 \\
\hline Groups & $-2,805$ & 0,940 & $-0,443$ & $-2,983$ & 0,005 \\
\hline
\end{tabular}

Note: histoscore TNF- $\alpha ; \mathrm{p}=0,148$

Groups score $(0=$ non-hydrosalpinx, 1 = hydrosalpinx $)$

\section{Discussion}

In inflammation caused by intracellular pathogens, cytokines such as TNF-a tend increase due to the induction of macrophages. TNF-a modulates cellular proliferation, differentiation, and immunoregulation, which are important in regulating inflammation, defense, immune response and apoptosis [7]. The presence of TNF-a also serves as a host defense in the elimination of tumor cells, microorganisms and parasitic pathogens [13]. The inflammation effect on the endometrium is caused by the presence of hydrosalpinx fluid, in contrast to the normal tubal fluid, which enters the endometrium and activates macrophages $[14,15]$. In addition to this macrophage activation mechanism, TNF- $\alpha$ in the hydrosalpinx fluid also triggers TNF-a expression in the endometrium. TNF-a potential induces increased TNF-a expression in TNF-a-induced cells [16]. Bedaiwy MA et al. found that TNF-a is present in all hydrosalpinx fluid samples [6].

The results of the present study found TNF-a expression in non-hydrosalpinx group, since TNF- $a$ is normally expressed by endometrial tissue and myometrial muscle cells [17]. The role of TNF-a in regulating the physiological state in the human body, such as the excessive amount in the mid-secretion phase of the menstrual cycle, suggests that TNF-a plays an important role in the changes in endometrial tissue associated with this response. In addition, Phillippeaux and Piquet [18] showed the role of TNF-a in the endometrial apoptosis pathway, and additionally, excess TNF-a production in the spiral arteries may play a role in menstruation. The induction of endometrial cell apoptosis by TNF-a occurs through several signaling pathways. Among these pathways is NFKB activation, which then triggers an increase in other proinflammatory cytokines by activating proapoptotic proteins, such as caspase. Endometrial cell apoptosis plays an important role in the regulation of endometrial function, during both the menstrual cycle and implantation. The implantation process requires apoptosis. Impaired apoptotic mechanisms 
that occur in endometrial cells may affect endometrial receptivity, which then impacts implant failure [19]. Increased apoptosis in endometrial cells can also directly cause endometrial tissue damage. This damage can subsequently have an impact on decreased endometrial receptivity. This condition induces the risk and incidence of increased infertility in patients with hydrosalpinx.

In the present study, caspase-9 expression in endometrial hydrosalpinx patients was significantly increase when compared with that in endometrium of patients without hydrosalpinx. This effect is due to the hydrosalpinx pathophysiology that might include the expression abnormalities of several molecules as well as the accumulation of hydrosalpinx fluid, which disturbs the ideal endometrium conditions and triggers apoptosis [19]. Apoptosis in this condition is closely related to TNF-a produced in hydrosalpinx. Increased caspase-9 expression indirectly suggests the activation of caspase- 9 , as a mechanism involving the mitochondria mediated by mitochondrial outer membrane permeabilization [20]. This finding suggests that the apoptosis event occurs through an intrinsic pathway. The presence of caspase9 expression in the endometrium is also found in other pathological conditions in addition to hydrosalpinx, i.e., endometriosis. Madjid et al. showed an increase in caspase-9 expression in the endometrium of endometriosis patients based on the examination of menstrual cells [21]. This finding shows that the presence of endometriosis will affect the fluid peritoneum and uterine cavity conditions, which then trigger increased caspase-9 activation in the endometrium.

Neither the physiological nor pathological states described above require apoptotic suppressant factors (anti-apoptotic); Hsp70 has anti-apoptotic and cytoprotective properties, and its function is to induce cells to inactivate apoptosis, thereby promoting cell survival by preventing protein denaturation, facilitating the transfer of proteins between organelles and cell membranes, as well as maintaining the integrity of regulator proteins [22]. Hsp70 inhibits apoptotic pathways dependent on the Bid-dependent apoptotic pathway (T-Bid) [23], which directly binds to Apaf-1 and prevents Bax in intrinsic pathways to enter the mitochondrial outer membrane, thus preventing mitochondrial membrane permeabilization as well as cytochrome c release [24]. Hsp70 indirectly prevents apoptotic pathways involving caspase [25]. As predicted, the expression of Hsp70 in the endometrium of hydrosalpinx patients will be decreased. In the present study, Hsp70 expression in the hydrosalpinx group was lower than that in the non-hydrosalpinx group. High apoptotic activity in hydrosalpinx patients suppressed Hsp70 cytoprotective activity and consequently decreased the expression of this protein. TNF- $a$ and caspase-9 are closely related to apoptotic activity, whereas Hsp70 shows anti-apoptotic activity, suggesting that Hsp70 has inverse functions with both proteins. Increased apoptosis will decrease uterus reproductive capacity and is related to endometrial receptivity to the fertilization product.

LIF plays an important role and becomes an important marker for endometrial receptivity [26]. These compounds are predominantly produced in endometrial epithelial cells and are also expressed by embryos, and the levels of these compounds increase during implantation [27]. LIF is highly expressed in the endometrium starting from mid-secretion until the final secretion phase (day 18 and 28) with a peak on the 20th day of the menstrual cycle and early in pregnancy [28]. In the present study, LIF in hydrosalpinx are lower than the non-hydrosalpinx group. This finding indirectly indicates that the 
presence of hydrosalpinx tends to affect endometrial receptivity. The low level of receptivity in the hydrosalpinx group is caused by the entrance of hydrosalpinx fluid into the uterine cavity, which then affects the uterine cavity environment so that cytokine communication during implantation of the embryo becomes disrupted.

Zhong et al. showed that the expression of LIF in hydrosalpinx patients was significantly different before and after hydrosalpinx surgery [11]. LIF levels in hydrosalpinx patients before surgery were lower compared to the levels observed after surgery. This result indicates the proapoptotic mediator effect of hydrosalpinx, as previously described, in suppressing the effect of this LIF and indirectly describing the state of the implantation window in hydrosalpinx. Hydrosalpinx fluid can act on different target systems: directly on the embryo, endometrial receptivity or even both. LIF regulates events during implantation, such as endometrial receptive conditions, endometrial embryonic interactions, stromal desidualization, blastocyst invasion and blastocyst development [29]. In addition, LIF also regulates prostaglandin synthesis, which acts as an important mediator in implantation and decidualization [30]. Ultimately, the important roles of LIF have implications on the outcomes of assisted reproduction technologies. For future perspectives, information on the low endometrial LIF concentrations during the window of implantation in patients during embryo transfer preparation and recombinant human LIF therapy may improve implantation success. Mezhevikina et al. examined an LIF recombinant in mice, demonstrating that recombinant LIF acts as a membrano-tropic agent affecting lipid bilayer viscosity, increasing positive charge and cell membrane conductivity [31]. The role of LIF in the success of implantation has implications for the fertility rates of women and becomes a receptive endometrial marker that is often affected by the pathological state in the vicinity.

The association of TNF-a, caspase-9 and Hsp70 with LIF or endometrial receptivity is an explanatory causal relationship based on the pathophysiology of this condition. Existing studies show consistent results for the negative effects of fluid generated via processes occurring in the hydrosalpinx state. Some studies have shown the toxic effect of hydrosalpinx fluid in relation to fertility [32]. Evidence of this adverse effect is derived from several conditions, including infertility problems in undergoing hydrosalpinx to failure of assisted reproductive therapy techniques in achieving successful postimplantation embryo implantation either frozen or not in hydrosalpinx patients.

The present study will attempt to characterize the etiopathogenesis of the hydrosalpinx link to decreased endometrial receptivity through the mechanisms of proteins involved in the apoptotic pathway. The presence of hydrosalpinx fluid in the cavity uteri will activate macrophages, thus increasing TNF-a in the uterine cavity. The present study demonstrated that the expression of TNF- $a$ in the endometrium with hydrosalpinx is greater than without hydrosalpinx. The high expression of TNF-a in hydrosalpinx patients will activate an apoptosis cascade through an extrinsic pathway. Extrinsic path apoptosis begins with the release of signal molecules called ligands by other cells but not from cells that undergo apoptosis. In this case, TNF-a is a ligand or product produced outside the endometrial cell that binds to the cell surface receptor and is never directly involved in endometrial cells. The ligand binds to the death receptor on the target cell membrane, which then induces apoptosis via the death domain. This mechanism may explain 
why TNF-a does not directly contribute to LIF as an endometrial receptivity marker predominantly produced by endometrial epithelial cells, whereas TNF- $a$ is a product produced outside of endometrial cells. TNF-a binds to tumor necrosis factor receptor type 1 on the surface of endometrial cells, which then activates the tumor necrosis factor receptor type 1-associated death domain (TRADD) contained in endometrial cells. TRADD then binds Fas-associated protein with death domain (FADD), which will activate caspase-8 in an extrinsic pathway. Since the production of LIF occurs in the endometrial cells, the association of TNF-a in endometrial (LIF) endocrine through apoptotic pathways can be indirectly assessed by examining TRADD expression in endometrial cells. This finding is a limitation in the present study, since TNF-a expression has only been characterized without the examination of TRADD expression.

In the present study, the expression of caspase-9 and Hsp70 with LIF on endometrium showed that caspase-9 expression, as an intrinsic apoptotic pathway, has a higher yield in hydrosalpinx patients. Hsp70 is synonymous with cytoprotective properties and anti-apoptosis has a lower yield in hydrosalpinx patients. Hsp70 plays a significant role in suppressing mitochondrial-intrinsic apoptotic pathways. High apoptosis can suppress the expression of Hsp70 in endometrial cells [33]. The high expression of caspase-9 and the low expression of Hsp70 suggest that there is a high apoptotic process in hydrosalpinx patients. In contrast to TNF-a originating from outside the endometrial cells, the formation of both caspase-9 and Hsp70 occurs within endometrial cells as well as through the formation of LIF derived from endometrial cells, and the present study showed that both proteins contribute to the value of LIF.

\section{Limitation Of The Study}

The present study has some limitations, as only four proteins that observed in the path of apoptosis caused decreasing endometrial prescriptions of hydrosalpinx patients. There are many mechanisms and proteins involved in apoptosis that require further study. Another limitation is the indirect assessment of the association of endometrial receptivity with expressed proteins by immunohistochemical examination. For further perspective, the hydrosalpinx mechanisms and decreased endometrial prescriptions should be directly assessed.

\section{Conclusion}

The present study explained the etiopathogenesis of infertility under hydrosalpinx conditions that focused on endometrial receptivity by using LIF markers. We concluded that several factors, namely, caspase-9, Hsp70 and LIF, are interconnected and related to the occurrence of impaired receptivity in the endometrium of hydrosalpinx patients. However, these findings were obtained through an indirect approach; further study is required to directly determine the correlation among variables through experimental studies.

\section{Declarations}




\section{Ethics Approval and Consent to Participate}

This study was approved by Faculty of Medicine Ethics Committee Review Board, Universitas Padjadjaran and all participants gave informed consent, patients consent to participate was written. Authors hereby declare that patients have been examined in accordance with the ethical standards laid down in the 1964 Declaration of Helsinki.

\section{Consent to Publish}

All authors declare that written informed consent was obtained from each patient details for publication of this study and accompanying images to be published.

\section{Availability of data and materials section}

Authors declare that the data will not be shared, since its patient confidentiality.

\section{Competing Interests}

Authors have declared that no competing interests exist.

\section{Funding}

No funding was obtained for this study

\section{Acknowledgements}

Not applicable.

\section{Authors' contributions}

HHS, TDJ, JSE, PSI, THM, WP carried out samples collection, participated in molecular assessment, and drafted the manuscript. HHS, THM, WP, and LS participated in design of the study and performed statistical analysis. HHS, TDJ, WP, and LS conceived the study and participated in its design and coordination, and helped drafting the manuscript. All authors has read and approved of the final manuscript.

\section{References}

1. Mascarenhas MN, Flaxman SR, Boerma T, Vanderpoel S, Stevens GA. National, regional, and global trends in infertility prevalence since 1990: a systematic analysis of 277 health surveys. PLoS Med. 2012;9(12):e1001356.

2. Rutstein SO, Shah IH. Infecundity, Infertility, and Childlessness in Developing Countries. WHO 2004. http://www.who.int/reproductivehealth/topics/infertility/DHS-CR9.pdf. 
3. Practice Committee of the American Society for Reproductive Medicine. Role of tubal surgery in the era of assisted reproductive technology: a committee opinion. Fertil Steril. 2015 Jun;103(6):e37-43.

4. Mårdh PA. Tubal factor infertility, with special regard to chlamydial salpingitis. Curr Opin Infect Dis. 2004 Feb;17(1):49-52..

5. Chu J, Harb HM, Gallos ID, Dhillon R, Al-Rshoud FM, Robinson L, Coomarasamy A. Salpingostomy in the treatment of hydrosalpinx: a systematic review and meta-analysis. Hum Reprod. 2015 Aug;30(8):1882-95.

6. Bedaiwy MA, Falcone T, Goldberg JM, Attaran M, Sharma R, Miller K, Nelson DR, Agarwal A. Relationship between cytokines and the embryotoxicity of hydrosalpingeal fluid. J Assist Reprod Genet. 2005 Apr; 22(4): 161-165.

7. Le J, Vilcek J. Tumor necrosis factor and interleukin 1: cytokines with multiple overlapping biological activities. Lab Invest. 1987 Mar;56(3):234-48.

8. Huai J, Jöckel L, Schrader K, Borner C. Role of caspases and non-caspase proteases in cell death. F1000 Biol Rep. 2010; 2: 48.

9. Chandra D, Tang DG. Mitochondrially localized active caspase-9 and caspase-3 result mostly from translocation from the cytosol and partly from caspase-mediated activation in the organelle. Lack of evidence for Apaf-1-mediated procaspase-9 activation in the mitochondria. J Biol Chem. 2003 May 9;278(19):17408-20.

10. Beere HM, Green DR. Stress management -heat shock protein-70 and the regulation of apoptosis. Trends Cell Biol. 2001 Jan;11(1):6-10.

11. Zhong Y, Li J, Wu H, Ying Y, Liu Y, Zhou C, Xu Y, Shen X, Qi Q. Effect of surgical intervention on the expression of leukemia inhibitory factor and L-selectin ligand in the endometrium of hydrosalpinx patients during the implantation window. Exp Ther Med. 2012 Dec; 4(6): 1027-1031.

12. McCarty KS Jr, Miller LS, Cox EB, Konrath J, McCarty KS Sr. Estrogen receptor analyses. Correlation of biochemical and immunohistochemical methods using monoclonal antireceptor antibodies. Arch Pathol Lab Med. 1985;109:716-21

13. Levine SJ, Larivee P, Logun C, Angus CW, Ognibene FP, Shelhamer JH. Tumor necrosis factor-alpha induces mucin hypersecretion and MUC-2 gene expression by human airway epithelial cells. Am J Respir Cell Mol Biol. 1995;12(2):196-204

14. Strandell A, Lindhard A. Why does hydrosalpinges reduce fertility? The importance of hydrosalpinx fluid. Hum Reprod. 2002;17:1141-5.

15. Ng EHY, Ajonuma LC, Lau EYL, Yeung WSB, Ho PC. Adverse effects of hydrosalpinx fluid on sperm motility and survival. Hum Reprod. 2000;15(4):727-77

16. Naude PJ, den Boer JA, Luiten PG, Eisel UL. Tumor necrosis factor receptor cross-talk. FEBS J. 2011;278(6):888-98

17. Haider S, Knöfler M. Human tumour necrosis factor: physiological and pathological roles in placenta and endometrium. Placenta. 2009;30(2):111-23 
18. Philippeaux MM, Piguet PF. Expression of tumor necrosis factor-alpha and its mRNA in the endometrial mucosa during the menstrual cycle. Am J Pathol. 1993;143(2):480-6

19. Mansour RT, Aboulghar MA, Serour GI, Riad R. Fluid accumulation of the uterine cavity before embryo transfer: a possible hindrance for implantation. J In Vitro Fert Embryo Transf. 1991;8(3):157-9

20. Galluzzi L, Vitale I, Abrams JM, Alnemri ES, Baehrecke EH, Blagosklonny MV, et al. Molecular definitions of cell death subroutines: recommendations of the Nomenclature Committee on Cell Death 2012. Cell Death Differ. 2012;19(1):107-20.

21. Madjid T, Hernowo B, Maskoen A, Achmad T, Jacoeb T, Biben A. The relationship of caspase-3, caspase-9, matrixmetalloproteinase-9 protein expression and C-1562T MMP-9 gene polymorphism in menstrual blood as the etiopathogenesis marker to clinical endometriosis manifestation in the establishment of its diagnosis. Am J Res Comm. 2015;3(9):100-24

22. Parsell DA, Lindquist S. The function of heat-shock proteins in stress tolerance: degradation and reactivation of damaged proteins. Annu Rev Genet. 1993;27:437-96

23. Mosser DD, Caron AW, Bourget L, Meriin AB, Sherman MY, Morimoto RI, Massie B. The chaperone function of hsp70 is required for protection against stress-induced apoptosis. Mol Cell Biol. 2000;20(19):7146-59.

24. Stankiewicz AR, Lachapelle G, Foo CP, Radicioni SM, Mosser DD. Hsp70 inhibits heat-induced apoptosis upstream of mitochondria by preventing Bax translocation. J Biol Chem. 2005;280(46):38729-39

25. Creagh EM, Carmody RJ, Cotter TG. Heat shock protein 70 inhibits caspase-dependent and independent apoptosis in Jurkat T cells. Exp Cell Res. 2000;257(1):58-66.

26. Senturk LM, Arici A. Leukemia inhibitory factor in human reproduction. Am J Reprod Immunol. 1998;39(2):144-51

27. Arici A, Engin O, Attar E, Olive DL. Modulation of leukemia inhibitory factor gene expression and protein biosynthesis in human endometrium. J Clin Endocrinol Metab. 1995;80(6):1908-15

28. Perrier d'Hauterive S, Charlet-Renard C, Berndt S, Dubois M, Munaut C, Goffın F, Hagelstein MT, Noël A, Hazout A, Foidart JM, Geenen V. Human chorionic gonadotropin and growth factors at the embryonic-endometrial interface control leukemia inhibitory factor (LIF) and interleukin 6 (IL-6) secretion by human endometrial epithelium. Hum Reprod. 2004;19(11):2633-43.

29. Salleh N, Giribabu N. Leukemia inhibitory factor: roles in embryo implantation and in nonhormonal contraception. Scientific World 2014;2014:201514

30. Horita H, Kuroda E, Hachisuga T, Kashimura M, Yamashita U. Induction of prostaglandin E2 production by leukemia inhibitory factor promotes migration of first trimester extravillous trophoblast cell line, HTR-8/SVneo. Hum Reprod. 2007;22(7):1801-9

31. Mezhevikina LM, Petrova RR, Borisova MP, Seraya OY, Fesenko EE. Effects of Recombinant Leukemia Inhibitory Factor (LIF) on Functional Status of Mouse Embryonic Stem Cells. Embryonic Stem Cells: The Hormonal Regulation of Pluripotency and Embryogenesis. 2011 
32. Andersen AN, Yue Z, Meng FJ, Petersen K. Low implantation rate after in-vitro fertilization in patients with hydrosalpinges diagnosed by ultrasonography. Hum Reprod. 1994;9(10):1935-8

33. Ravagnan L, Gurbuxani S, Susin SA, Maisse C, Daugas E, Zamzami N, Mak T, Jäättelä M, Penninger JM, Garrido C, Kroemer G. Heat-shock protein 70 antagonizes apoptosis-inducing factor. Nat Cell Biol. 2001;3(9):839-43.

\section{Figures}

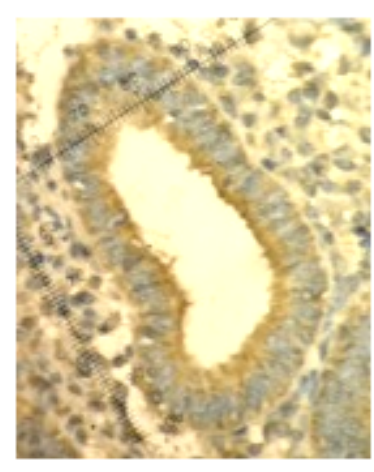

A

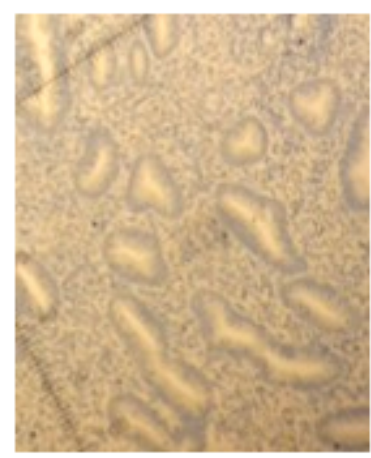

D

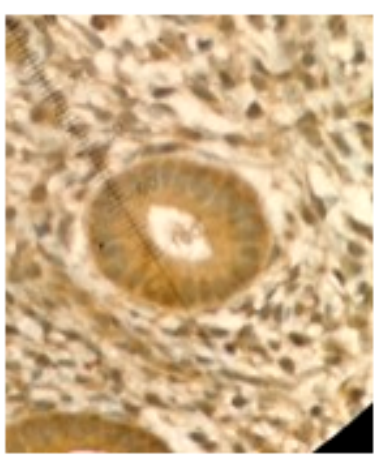

B

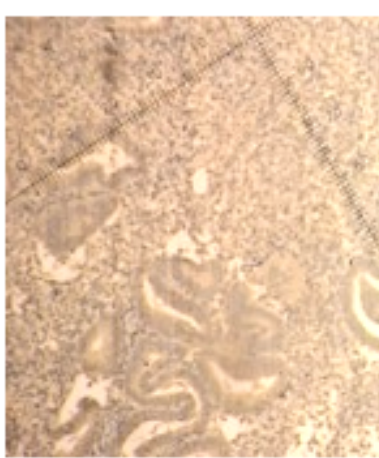

$\mathbf{E}$

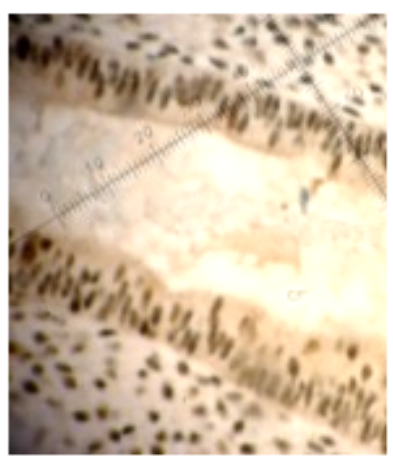

C

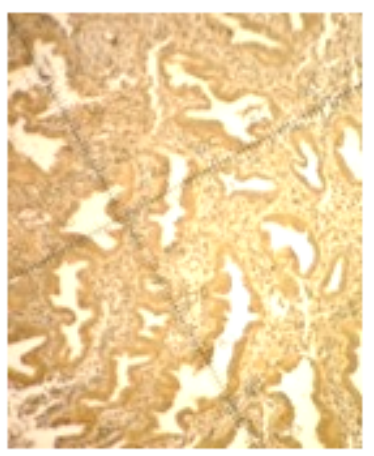

$\mathbf{F}$

\section{Figure 1}

TNF-a Expression Observed by Imunohistochemistry A. TNF-a endometrium expression with low intensity (400x) B. TNF-a endometrium expression with moderate intensity (400x) C. TNF-a endometrium expression with strong intensity (400x) D. TNF-a endometrium expression with $20-50 \%$ distribution (100x) E. TNF-a endometrium expression with 50-80\% distribution (100x) F. TNF-a endometrium expression with $>80 \%$ distribution $(100 \mathrm{x})$ 


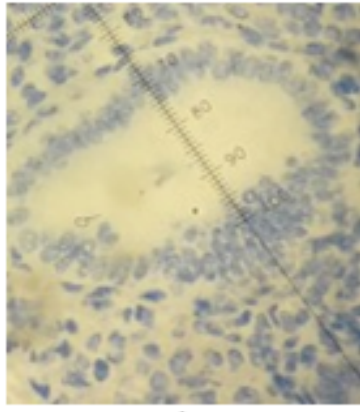

A

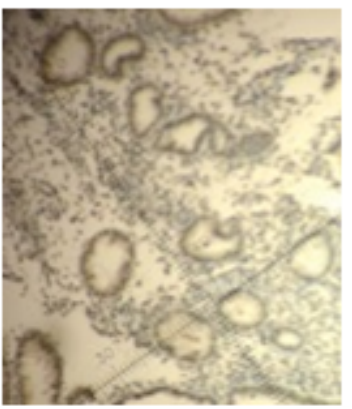

D

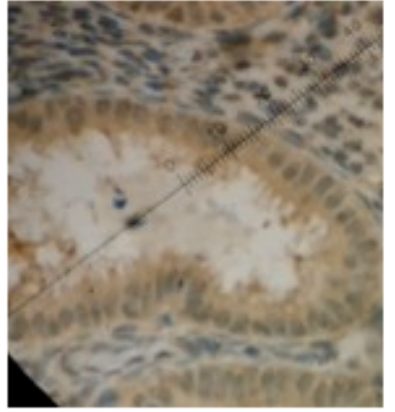

B

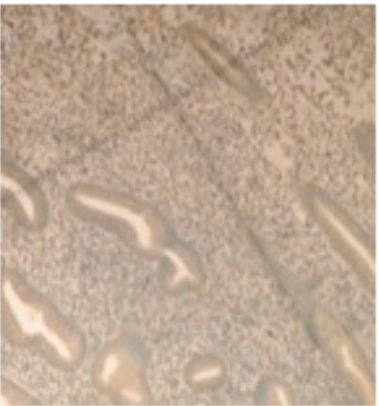

$\mathbf{E}$

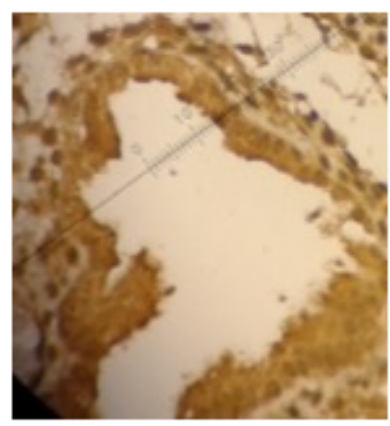

C

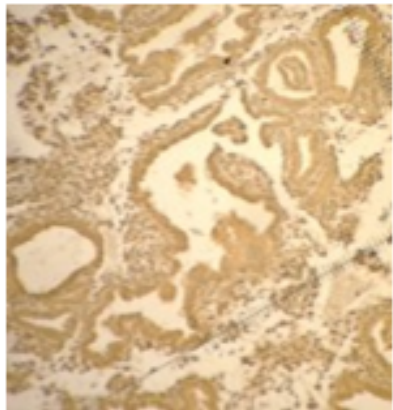

$\mathbf{F}$

Figure 2

Caspase-9 Expression Observed by Imunohistochemistry A. Caspase-9 endometrium expression with low intensity (400x) B. Caspase-9 endometrium expression with moderate intensity (400x) C. Caspase-9 endometrium expression with strong intensity (400x) D. Caspase-9 endometrium expression with $20-50 \%$ distribution (100x) E. Caspase-9 endometrium expression with 50-80\% distribution (100x) F. Caspase-9 endometrium expression with $>80 \%$ distribution (100x)

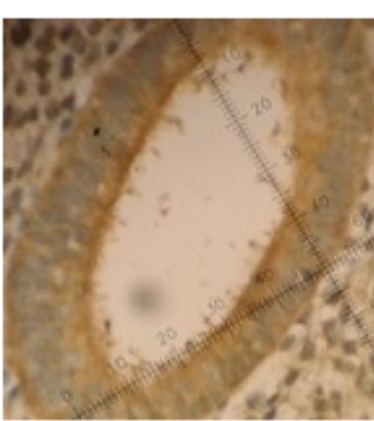

A

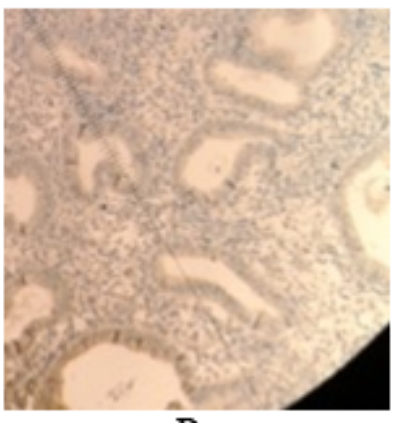

D

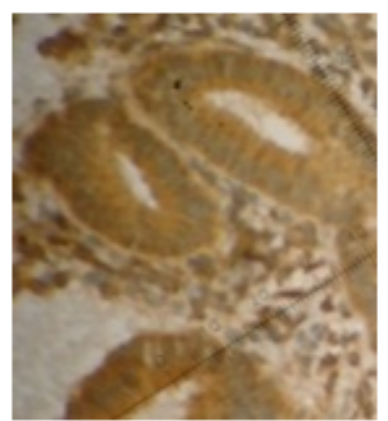

B

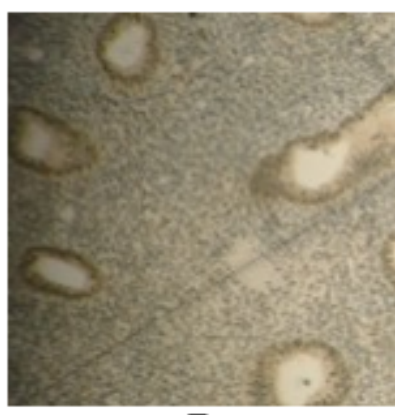

$\mathbf{E}$

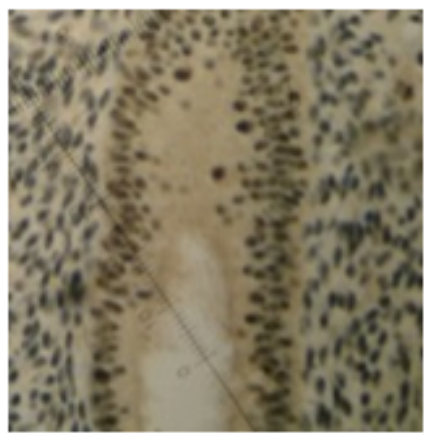

$\mathbf{C}$

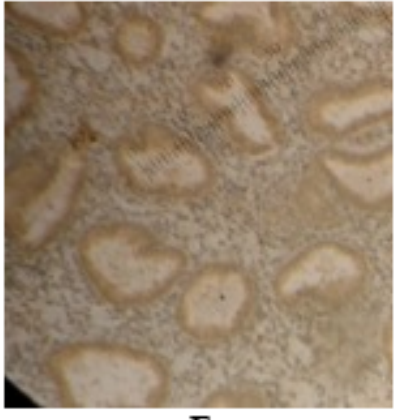

F 


\section{Figure 3}

Hsp70 Expression Observed by Imunohistochemistry A. Hsp70 endometrium expression with low intensity (400x) B. Hsp70 endometrium expression with moderate intensity (400x) C. Hsp70 endometrium expression with strong intensity (400x) D. Hsp70 endometrium expression with 20-50\% distribution (100x) E. Hsp70 endometrium expression with 50-80\% distribution (100x) F. Hsp70 endometrium expression with $>80 \%$ distribution $(100 x)$

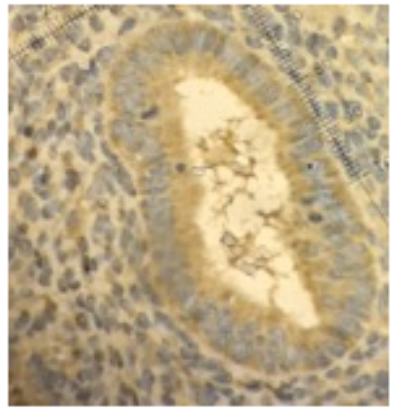

A

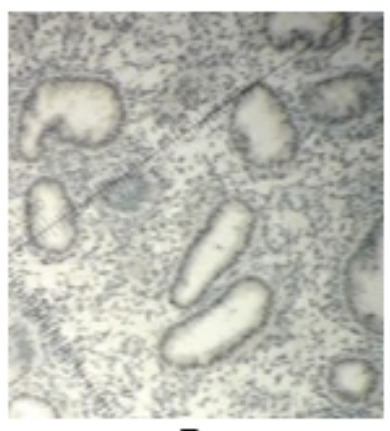

D

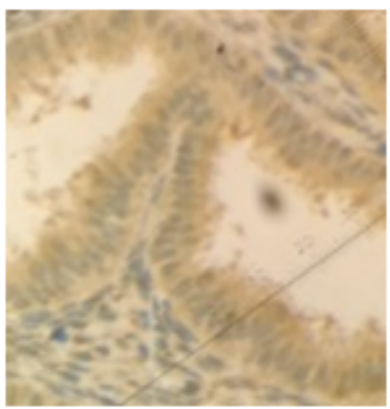

B

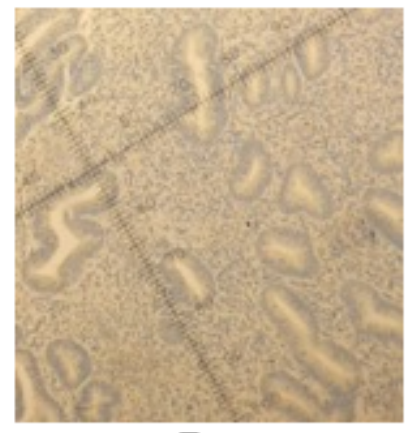

E

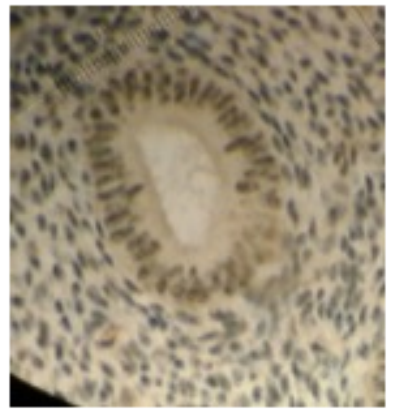

C

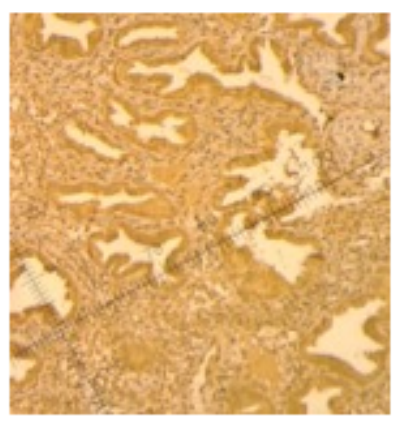

F

\section{Figure 4}

LIF Expression Observed by Imunohistochemistry A. LIF endometrium expression with low intensity (400x) B. LIF endometrium expression with moderate intensity (400x) C. LIF endometrium expression with strong intensity (400x) D. LIF endometrium expression with 20-50\% distribution (100x) E. LIF endometrium expression with $50-80 \%$ distribution (100x) F. LIF endometrium expression with $>80 \%$ distribution (100x) 